\title{
Resolution of organic racemates via host-guest enantioselective inclusion complexation in bile acid derivatives
}

\author{
O. Bortolini, ${ }^{a, *}$ G. Fantin, ${ }^{b}, *$ M. Fogagnolo, ${ }^{b}$ and S. Maietti ${ }^{b}$ \\ ${ }^{a}$ Dipartimento di Chimica, Università della Calabria, Arcavacata (CS), Italy \\ ${ }^{b}$ Dipartimento di Chimica, Università di Ferrara, Ferrara, Italy \\ E-mail: o.bortolini@unical.it and fnn@unife.it
}

\section{Dedicated to Prof. G. Bartoli, University of Bologna, on the occasion of his 65th birthday}

\begin{abstract}
We describe the utilization of bile acids as hosts for molecular recognition and enantioselective enclathration during recent years in our laboratories. The optical resolution of different classes of organic derivatives, i.e., sulfoxides, epoxides, ketones, cyclic amides, has been obtained by hostguest enantioselective inclusion complexation. The salient aspects of the process, including Xray results, are discussed.
\end{abstract}

Keywords: Enantioresolution, host-guest complexation, enclathration, bile acids

\section{Contents}

Introduction

1. Resolution of Organic Racemates

1.1 Resolution of sulfoxides

1.2 Resolution of cyclic ketones

1.3 Resolution of epoxides

1.4 Resolution of cyclic amides

2. Conclusions

\section{Introduction}

Bile acids, their conjugates and salts are natural products, fundamental constituents of bile. ${ }^{1-3}$ Beside their role in the emulsification of bile lipids, and as end products of cholesterol metabolism, bile acids occupy a central position in the understanding of the role of steroids in 
biological systems. The primary bile acids in human bile (see Fig. 1) are cholic acid 1

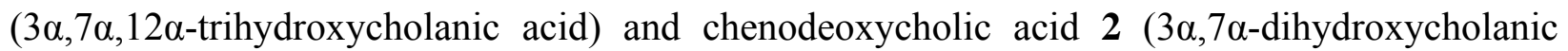
acid), mainly present as glycine and taurine conjugates $\left(-\mathrm{NHCH}_{2} \mathrm{COO}^{-}\right.$and $-\mathrm{NHCH}_{2} \mathrm{CH}_{2} \mathrm{SO}_{3}{ }^{-}$at C-24).<smiles>C[C@H](CCC(=O)O)C1CCC2C3C(C[C@H](O)[C@@]21C)[C@@]1(C)CC[C@H](O)CC1C[C@H]3O</smiles>

CA 1

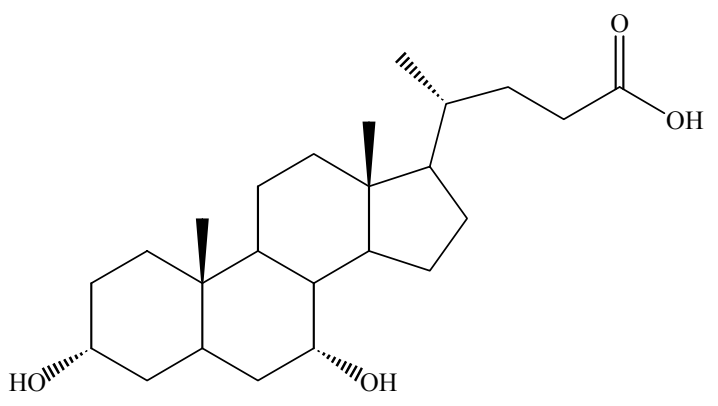

CDCA 2<smiles>C[C@H](CCC(=O)O)C1CCC2C3CCC4C[C@@H](O)CC[C@]4(C)C3C[C@H](O)[C@@]21C</smiles>

DCA 3<smiles>C[C@H](CCC(=O)O)C1CCC2C3CCC4C[C@@H](O)CC[C@]4(C)C3CC[C@@]21C</smiles>

LCA 4<smiles>C[C@H](CCC(=O)O)C1CCC2C3C(=O)CC4CC(=O)CC[C@]4(C)C3CC(=O)[C@@]21C</smiles>

DHC 5

Figure 1. Structures and acronyms of selected bile acids.

The secondary bile acids include derivatives of deoxycholic $\mathbf{3}$ and lithocholic acids $\mathbf{4}$, produced by $\mathrm{C}(7)$ - dehydroxylation by intestinal bacteria. ${ }^{4,5}$ Cholic-, chenodeoxycholic-, 
ursodeoxycholic acids and its 7-hydroxy epimer have important pharmaceutical applications related to their ability to dissolve cholesterol gallstones and for the treatment of bile-acid deficiency and cholestatic liver diseases. ${ }^{6}$ Beside the pharmacological applications, there is increasing interest in the use of bile acids as building blocks of supramolecular hosts for molecular recognition. ${ }^{7-11}$ In this process a host molecule spatially incorporates a guest molecule or ion within its confines. Therefore, the precise control of host cavities for guest recognition is a basic requirement in order to obtain selective and efficient accommodation processes. Molecules with well-defined geometries and limited conformational freedom are ideal candidates for designing, building and controlling host cavities, and bile acids are particularly suitable for this, ${ }^{9-11}$ as demonstrated by the examples reported in the following Sections.

\section{Resolution of Organic Racemates}

In the enantioselective inclusion complexation of a racemic guest with a solid chiral host, one enantiomer of the former is separated as an inclusion host-guest complex crystal, ${ }^{12,13}$ (see Fig. 2). A number of inclusion procedures described in the literature may be grouped as: (a) absorption methods in which the insoluble host is left in the presence of the guest, or vice versa, for a given time; (b) crystallization methods in which the host is dissolved and recrystallized from the guest, and (c) solid-state inclusion consisting of a co-grinding of the two solid components in a mortar.

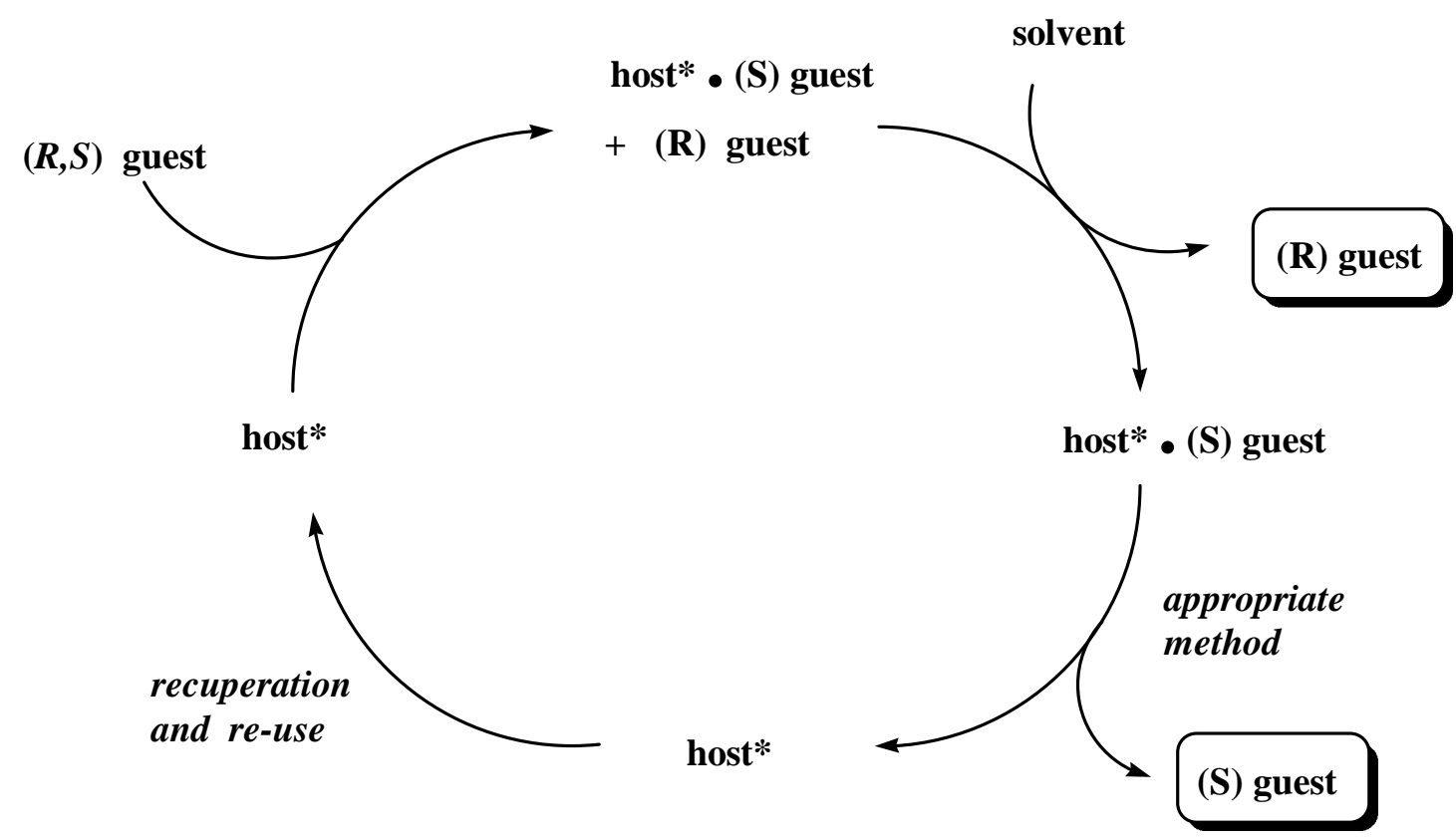

Figure 2. Enantioselective inclusion complexation of a racemic guest. The incorporation of the (S)- enantiomer is generic. 
From the inclusion crystal, an optically active guest can be isolated by an appropriate method such as extraction, distillation, or recrystallization, Fig. 2. The host may be recovered and used for further cycles. ${ }^{14}$ Note that if incomplete resolution takes place, repetition of the procedure on the partially resolved racemate guest increases the enantiomeric excess up to complete resolution. The enantiomeric excesses were usually obtained by GC analysis on a chiral column ${ }^{14}$ (Megadex DETTBS $\beta$ for the discussed cases) and absolute configurations were determined by comparison of $[\alpha]_{D}$ with literature values.

\subsection{Resolution of sulfoxides}

During the last few years we have published several papers ${ }^{14}$ on the optical resolution of different classes of organic molecules, mainly using cholic and dehydrocholic acids. In 2000 we reported the first example of an efficient optical resolution of a racemic organic sulfoxide by enclathration into dehydrocholic acid 5. ${ }^{15}$ The inclusion compounds of 5 with sulfoxides were obtained by two different methods based on direct absorption of the melted- (method A) or solvent-dissolved- (method B) sulfoxide. The choice depends uniquely on the sulfoxide. In the former case the solid dehydrocholic acid is directly added to the melted sulfoxide in the absence of any solvent, whereas in the latter procedure the selected sulfoxide was dissolved in the minimum amount of ethyl acetate, and poured onto solid 5. Both processes are equally effective, affording quantitative amounts of sulfoxide in good to high ee's. Selected examples are collected in Figure 3.

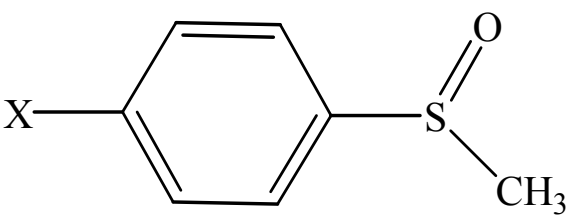

$\begin{array}{ll}\mathrm{X}=\mathrm{H} & \text { ee } 74 \% \\ \mathrm{X}=\mathrm{CH}_{3} & \text { ee } 99 \% \\ \mathrm{X}=\mathrm{OCH}_{3} & \text { ee } 54 \% \\ \mathrm{X}=\mathrm{Cl} & \text { ee } 82 \% \\ \mathrm{X}=\mathrm{Br} & \text { ee } 84 \%\end{array}$

Figure 3. Optical resolution of selected sulfoxides with $5 .^{15}$

Except for $\mathrm{X}=\mathrm{H}$, the absolute configurations of the included sulfoxides are assigned as (R)isomers. Interestingly, the separation-recovery process is developed, based on the acid-base properties of the reagents, i.e., alkaline treatment for releasing the included resolved guest and acid treatment for the recover of the host. No significant differences in optical and chemical yields were observed when a recycled dehydrocholic acid was used. X-ray analysis ${ }^{16}$ confirms that the inclusion complex has a 1:1 host:guest stoichiometry with a supramolecular architecture formed by intercalation layers. Further studies added evidence that dehydrocholic acid may be obtained in two polymorphic forms, named $\alpha$ - and $\beta$-, the latter being the thermodynamically more stable. ${ }^{17,18}$ The $\alpha$-form crystallizes in such a way that two independent molecules of 5 in the asymmetric unit are linked in dimers by two hydrogen-bonds between the carboxylic acid groups 
at $\mathrm{C}$-24, whereas in the $\beta$-form the two hydrogen-bonds are formed between the carboxylic acid functionality and the carbonyl group at C-3 (Figure 4). Of particular interest is the fact that the $\beta$ form may be transformed into the $\alpha$-phase by a guest-mediated solid state conversion, ${ }^{17,18}$ using $(R)-(+)$-methyl $p$-tolyl sulfoxide as the guest molecule, without decomposition or transition to amorphous states, as depicted in Figure 5.

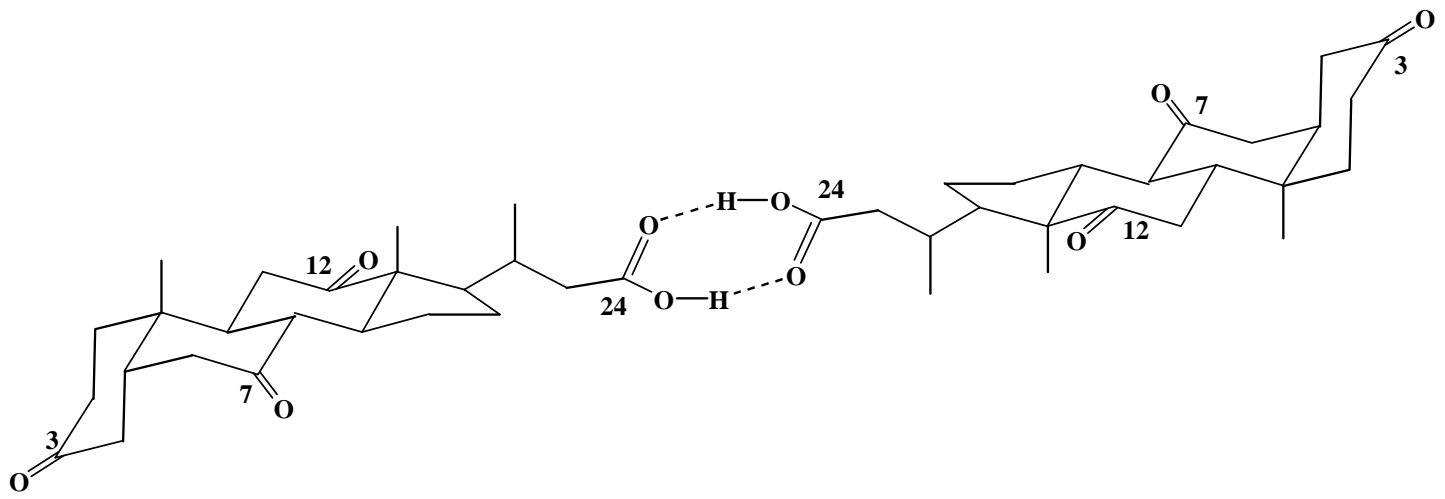

Dehydrocholic acid $\alpha$-form

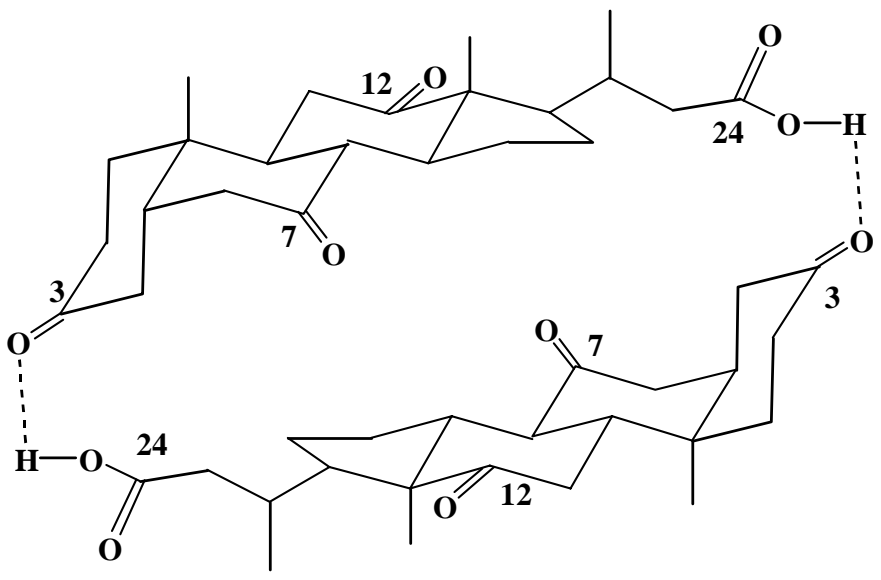

Dehydrocholic acid $\beta$-form

Figure 4. The two polymorphic forms of dehydrocholic acid.

\subsection{Resolution of Cyclic ketones}

The cholanoic acid derivatives $\mathbf{1}$ and $\mathbf{3}$ are active in the resolution of cyclic and bicyclic ketones. ${ }^{19}$ Host $\mathbf{3}$ is less specific than $\mathbf{1}$, forming inclusion compounds with many carbonyl derivatives, although all are characterized by a low level of resolution. Worth mentioning is the result obtained with the bicyclo[3.2.0]-hept-2-en-6-one, which is included in both hosts, but is resolved in the opposite configurations (-)-(1S,5R) or (+)-(1R,5S), as shown in Table 1. 

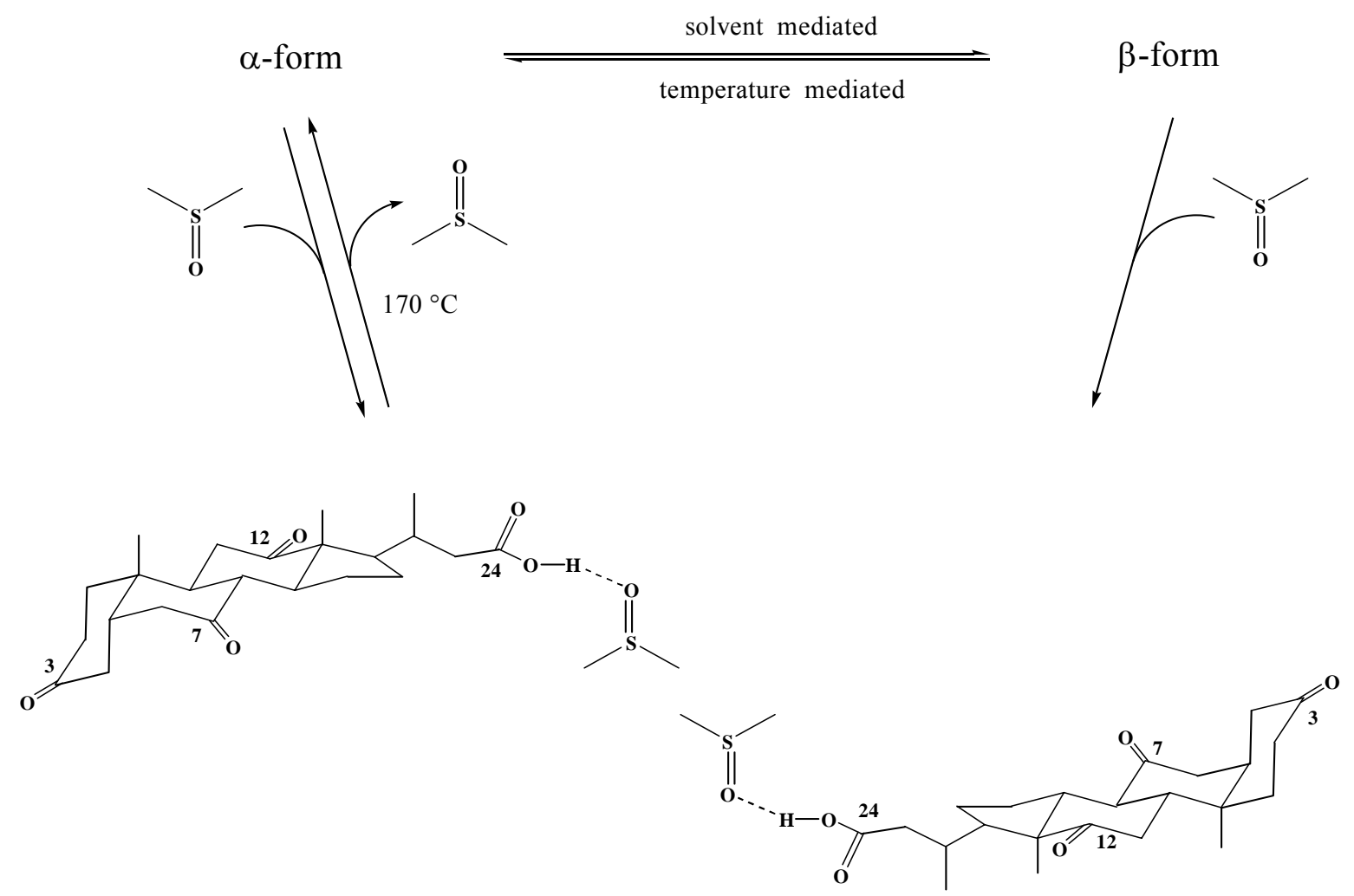

Figure 5. Conversion pathways for $\alpha / \beta$ forms.

Table 1. Optical resolution of selected cyclic ketones with 1 and 3

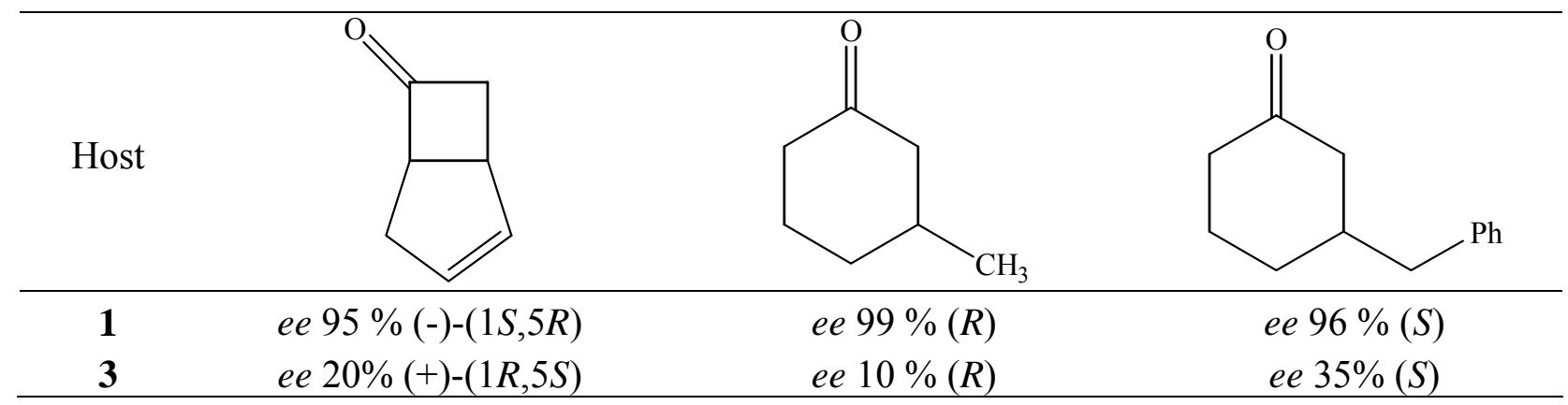

\subsection{Resolution of epoxides}

We have reported that the optical resolution of unfunctionalized epoxides may be achieved by inclusion in cholic acid 1. ${ }^{20}$ The presence of an aromatic substituent in the epoxide framework, probably associated with specific interactions within the host cavities, is determinant in order to observe good enantioselectivity. The experiments carried out on aliphatic epoxides, in fact, afforded very low enantiomeric excesses. In the majority of cases, the host:guest ratio was 2:1. The relevant results are collected in Table 2. 
Table 2. Optical resolution of epoxides with cholic acid

\begin{tabular}{ccccc}
\hline & & & $\begin{array}{c}\text { Epoxide absolute } \\
\text { configuration }\end{array}$ & $e e \%$ \\
& & $\mathrm{R}^{1}$ & & \\
& $\mathrm{Ph}$ & $\mathrm{H}$ & $(-)-\mathrm{S}, \mathrm{S}$ & $95 \%$ \\
$\mathrm{Me}$ & $\mathrm{H}$ & $(-)-\mathrm{S}, \mathrm{S}$ & $64 \%$ \\
& $\mathrm{Ph}$ & $\mathrm{Me}$ & $(+)-\mathrm{R}, \mathrm{R}$ & $67 \%$ \\
\hline
\end{tabular}

\subsection{Resolution of cyclic amides (lactams)}

Cyclic amides, whose derivatives quite reluctant towards resolution, may be enantiodifferentiated rather efficiently by using dehydrocholic acid 3 as the host molecule. ${ }^{21}$ Figure 6 collects three examples of this resolution after two-cycle-complexation. The bile-acid- to-amide inclusion ratio is generally $1: 1$, although some differences demonstrate the independence of the steric dimensions of the cyclic amide with respect to the inclusion stoichiometry.

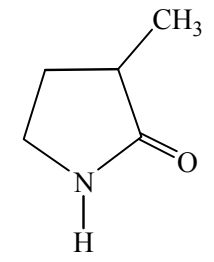

ee $80 \%(-)-(S)$

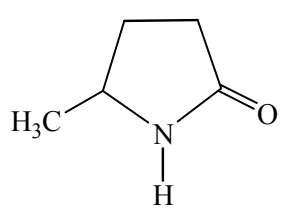

ee $92 \%(+)-(R)$

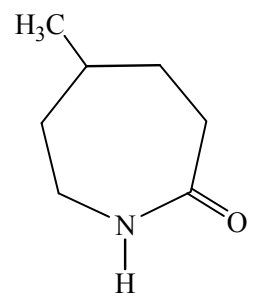

ee $94 \%(+)-(R)$

Figure 6. Optical resolution of selected amides with 3 ; ee values refer to two-cycles complexation.

\section{Conclusions}

To summarize, this short review reports a number of examples of racemate resolution by hostguest enantioselective inclusion complexation, with the aim of demonstrating the usefulness of this technique for the production of optically pure substances. ${ }^{14}$ The simple and straightforward procedures, the availability and low cost of the bile acid-derived hosts, and the mild experimental conditions are also important factors for the successful implementation of this type of enantioresolution on an industrial scale. 


\section{References}

1. Kritchevsky, D.; Nair P. P. The Bile Acids: Chemistry, Physiology and Metabolism, Plenum: New York, 1971; p 3.

2. Hylemon, P. B. In Sterols and Bile Acids; Danielsson. H.; Sjövall, J. Eds., Elsevier: Amsterdam, 1985, pp 331-343.

3. Hylemon, P. B.; Vallonee, D. H. Chimica Oggi 1991, 25.

4. Bortolini, O.; Medici, A.; Poli, S. Steroids 1997, 62, 564.

5. Trends in Bile Acid Research; Paumgartner, G.; Stiehl, A.; Gerok, W., Eds., Kluwer Academic Publishers: Dordrecht, 1989.

6. Enhsen, A.; Kramer, W.; Wess, G. Drug Discovery Today 1998, 3, 409.

7. Comprehensive Supramolecular Chemistry; Lehn, J-M.; Atwood, J. L.; Davies, J. E. D.; MacNicol, D. D.; Vögtle, F., Eds., Pergamon: New York, 1996; Vols.1-3.

8. Wallimann, P.; Marti, T.; Fürer, A.; Diederich, F. Chem. Rev. 1997, 97, 1567.

9. Tamminen, J.; Kolehmainen, E. Molecules 2001, 6, 21 and references cited therein.

10. Miyata, M.; Sada, K. Deoxycholic Acid and Related Hosts, in Comprehensive Supramolecular Chemistry; MacNicol, D. D.; Toda, F.; Bishop, R. Eds., Pergamon: New York; 1996, pp 147-176.

11. Davis, A. P.; Joos, J. B. Coord. Chem. Rev. 2003, 240, 143.

12. Enantiomer Separation. Fundamentals and Practical Methods; Toda, F. Ed., Kluwer Academic Publishers: Amsterdam, 2004.

13. Toda, F. Speciality Chemicals Magazine 2003, 23, 44.

14. Bortolini, O.; Fantin, G.; Fogagnolo, M. Chirality 2005, 17, 121.

15. Bortolini, O.; Fantin, G.; Fogagnolo, M.; Medici, A.; Pedrini, P. Chem. Commun. 2000, 365.

16. Bertolasi, V.; Bortolini, O.; Fantin, G.; Fogagnolo, M.; Medici, A. Chem. Lett. 2002, 400.

17. Fantin, G.; Fogagnolo, M.; Bortolini, O.; Masciocchi, N.; Galli, S.; Sironi, A. New J. Chem. 2003, 27, 1794.

18. Fantin, G.; Fogagnolo, M.; Bortolini, O.; Masciocchi, N.; Galli, S.; Sironi, A. New J. Chem. 2004, 28, 1295.

19. Bertolasi, V.; Bortolini, O.; Fogagnolo, M.; Fantin, G.; Pedrini, P. Tetrahedron Asymm. 2001, 12, 1479.

20. Bortolini, O.; Fantin, G.; Fogagnolo, M.; Medici, A.; Pedrini, P. Chem. Lett. 2000, 1246.

21. Bortolini, O.; Fantin, G.; Fogagnolo, M.; Medici, A. Chem. Lett. 2003, 32, 206.

\section{Authors' biographical data}

Olga Bortolini received a Laurea degree with honours in Chemistry from the University of Padova in 1979; Accademia dei Lincei research fellow at Padova University, 1980-1981. Researcher of the Italian National Research Council (CNR) since 1982. Post-doctoral research 
fellow at CNRS Laboratoire de Chimie de Coordination, Toulouse (France) in Prof. B. Meunier's group 1983. 1987-2003 Associate Professor of Organic Chemistry at the University of Ferrara. 2003 Full Professor of Organic Chemistry at the University of Calabria. June-August 1989, JuneJuly 1992 and April-May 1994 Visiting Professor at Purdue University, West Lafayette IN, USA, in Prof. R.G. Cooks' group. Author of about a hundred of papers in international journals, many reviews, book chapters and two patents.

Giancarlo Fantin was born in Torino in 1954. He received his degree in Chemistry from the University of Ferrara (1980) where he has been a researcher in Organic Chemistry since 1990. $\mathrm{He}$ is a co-author of over 90 publications and several patents in the area of organic synthesis, biotransformations and chiral recognition. 